bed attacking Pattie. Her first "waking" memory was of running from Pat's room out of the house to her sister living next door when she said "I think I've hurt Pattie". She had indeed; she had struck the daughter with two axe blows to the head.

The defence case has been outlined by Morris (1951) and the relevant part reads as follows: Mrs Cogdon's story was supported by the evidence of her physician, a psychiatrist, and a psychologist. The burden of the evidence of all three, which was not contested by the prosecution, was that Mrs Cogdon was suffering from a form of hysteria with an overlay of depression, and that she was of a personality in which such dissociated states as fugues, amnesias, and somnambulistic acts were to be expected. They agreed that she was not psychotic, and that if she had been awake at the time of the killing no defence could have been spelt out under the McNaughton Rules. They hazarded no statement as to her motives, the idea of defence of the daughter being transparently insufficient. However, the psychologist and the psychiatrist concurred in hinting that the emotional motivation lay in an acute conflict situation in her relations with her own parents; that during marital life she suffered very great sexual frustration; and that she overcompensated for her own frustration by over-protection of her daughter. Her exaggerated solicitude for her daughter was a conscious expression of her subconscious emotional hostility to her, and the dream of ghosts, spiders and Koreans were projections of that aggression.

How manifold can be the possible motives for a "motiveless" killing.

It is suggested that this case, which is not cited by Oswald and Evans, is of importance to the literature on this subject whether or not the details of the evidence given can be accepted or not.

Suite 1, 8th Floor

118 Queen Street

Melbourne 3000

Australia

\section{A. A. BARTHOLOMEW}

\section{References}

MorRIs, N. (1951) Somnambulistic homicide: Ghosts, spiders and North Koreans. Res Judicatae, 5, 29-33.

\section{Day and Full Time Psychiatric Treatment}

DeAr Sir,

The use of day hospital care is an increasingly important part of comprehensive psychiatric treatment. We welcome new research in this area and we were particularly interested in the case for the economic benefits of day care, which was advanced in the recent articles by Dick et al (Journal, September 1985, 147, 246-253).

We feel, however, that research into day hospital care, especially the economic aspects, must take into account the utilisation of that resource. One important aspect of the under-utilisation of psychiatric day care is non-attendance or early default by patients who have been offered a place. The figures in the literature suggest that this may involve between $16 \%$ and $53 \%$ of referrals (Tyrer \& Remington, 1979; Guy et al, 1969; Herz et al, 1975). It is our clinical impression that this remains a significant problem.

We wonder if Dick et al, demonstrated a default rate and whether this showed any difference between the in-patient and day patient groups.

We would also be interested to know whether the intensive recruitment procedure used for the day hospital rate had any influence on drop-out in that group compared to day hospital attenders from other sources.

Royal Liverpool Hospital

IAN A. DAvidson

P.O. Box 147

Liverpool L69 3BX

Sefton General Hospital

Liverpool

DOMINIC F. CONNOLLY

\section{References}

Guy, W., Gross, M., Hogart, G. \& Dennis, H. (1969) A controlled evaluation of day hospital effectiveness. Archives of General Psychiatry, 20, 329-338.

Herz, M., Endicott, J. \& SPITzer, R. (1975) Brief hospitalisation of patients with families: initial results. American Journal of Psychiatry, 132, 413-418.

TYRER, P. J. \& REMINGTON, M. (1979) Controlled comparison of day hospital and outpatient treatment for neurotic disorders. Lancet, $i, 1014-1016$.

\section{Dr Dick Replies}

DeAr Sir,

With regard to early default seven of the patients initially allocated to day care were excluded prior to entry into the study - four because they then refused or became too ill, and three because after discharge they telephoned the day hospital to say they were coping effectively. After entry into the study two day patients and one in-patient left treatment against advice. Our relatively low overall early default rate for day treatment $(<20 \%)$ can be explained by the selection procedures outlined in our paper. 